\title{
Viewpoints on the Theory of Agricultural Energy Internet
}

\author{
Xueqian $F u^{*}$ and Feifei Yang \\ College of Information and Electrical Engineering, China Agricultural University, Beijing, China
}

Keywords: agricultural energy internet, agricultural electrification, agrivoltaic system, agricultural meteorology, low-carbon energy

\section{INTRODUCTION}

The industrial mode of cross-border integration of agriculture and new energy has brought synergistic economic benefits. Through the cross-border integration of new energy and agriculture, an agricultural energy internet (AEI) can not only realize the double income generation of electricity and agriculture, but also can use one land twice to save land lease costs (Fu et al., 2021). Hot topics in the area of rural vitalization in China include realizing the in-depth coupling and optimization of new energy and agriculture; improving energy utilization, grain yield and quality; reducing carbon pollution. However, the electrical engineering scholars do not conduct in-depth research on agricultural engineering, while the Chinese agricultural engineers do not conduct in-depth research on electrical engineering. The technical barriers in the two fields limit the coordinated development of agriculture and energy. In addition, the models in the respective fields of agricultural engineering and electrical engineering are rarely applied across borders. One of the great challenges is to propose a unified modeling framework in the fields of meteorology, agriculture and energy, so as to realize the integrated simulation of environment in facility agriculture, crop production and energy networks. The application values of developing the theory of AEI are mainly reflected through: A. Benefits of carbon cycle. Agrivoltaic systems can reduce the carbon emissions via efficiently utilizing of photosynthesis and photovoltaic (PV) panels on the greenhouse roof. B. Secure supply of electricity. The modern agricultural industrial parks adopt a clustered development mode with high load factor and high load density. Thus, a multi-source power supply is adopted to ensure a secure power supply in the AEI (Fu et al., 2020a). AEI breaks the segmentation of agriculture and energy systems, and strengthens the coupling interaction between the ubiquitous power internet of things and the agriculture internet of things. The comprehensive perception of environment in facility agriculture and energy networks maintain security of electricity supply in an agricultural region. C. Complementarity between agriculture and industry. The primary object of this study is to break down the barriers between electric power industry and agricultural industry. Promoting the win-win coexistence of electric power industry and agricultural industry is an important measure to promote the large-scale and economic development of AEI.

This article was submitted to Process and Energy Systems Engineering,

a section of the journal Frontiers in Energy Research

Received: 08 February 2022 Accepted: 15 February 2022 Published: 02 March 2022

Citation:

Fu $X$ and Yang F (2022) Viewpoints on the Theory of Agricultural

Energy Internet.

Front. Energy Res. 10:871772. doi: 10.3389/fenrg.2022.871772

\section{EXISTING TECHNOLOGY METHODOLOGIES}

This section has three main parts. First, the concept of an AEI is proposed in Section 2.1. Second, we analyze the integration of agricultural and energy systems in Section 2.2. Finally, we present the viewpoints of agricultural energy system simulation in Section 2.3.

\subsection{Concept}

The scale of rural energy consumption in China has increased significantly. However, the existing agricultural energy systems have poor coordination, low energy efficiency, and serious pollution, 


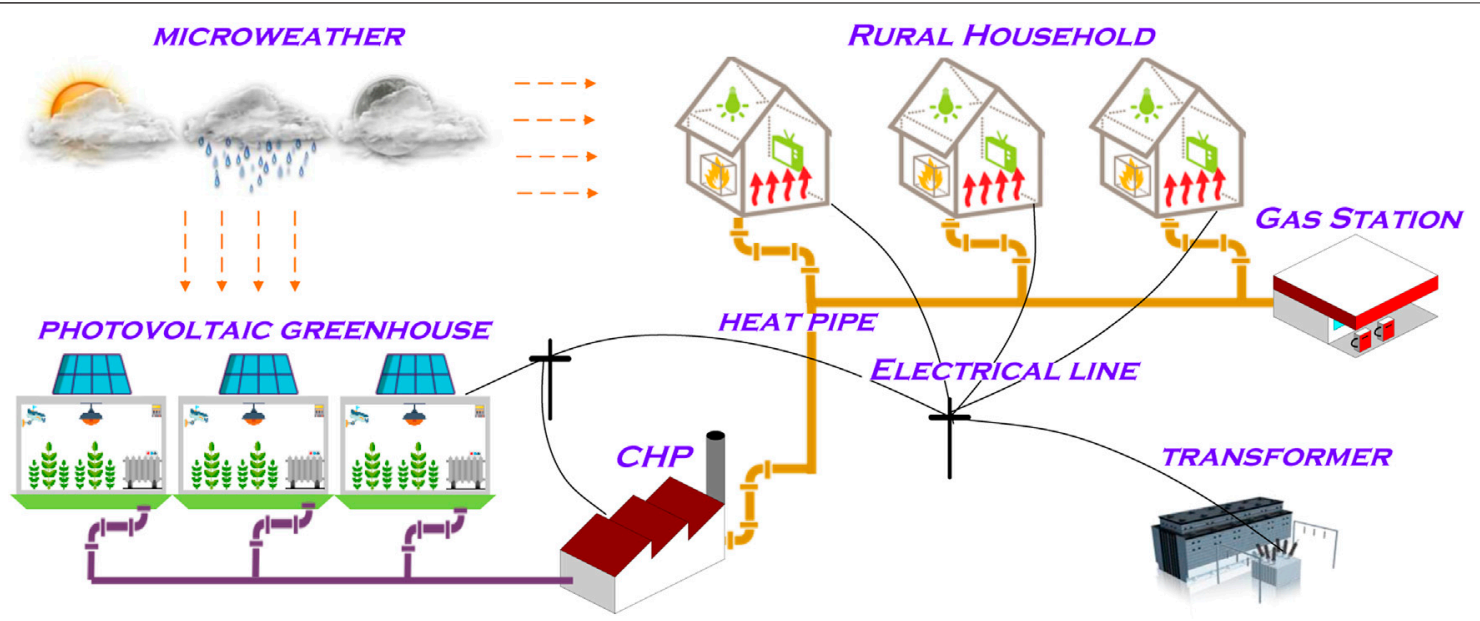

FIGURE 1 | Schematic diagram of the typical AEl consisting of agricultural and energy systems.

which have seriously hindered the development of intensive agricultural production. Hence, the development of the AEI is the key to achieving environment-energy-food synergistic security, and it is also an important driving force to promote the transformation of agricultural production to low-carbon, intelligence, intensification, and high-efficiency. The concept of an AEI is proposed as an energy solution for agriculture issues by integrating agricultural and energy systems (Xueqian, 2020), and the schematic diagram of the typical AEI is shown in Figure 1. An AEI can be identified by the following descriptions. A. The level of agricultural electrification is high, and agricultural production depends on electricity devices. B. The proportion of renewable energy generation is high, and an agrivoltaic system is an effective solution. C. Carbon capture, utilization and storage technologies should be applied across the agricultural energy networks. D. Weather change has significant economic and security impacts on agricultural production and new energy power generation.

\subsection{Integration Optimization of Agriculture and Energy}

Agriculture and energy are the two fundamental parts that make up an AEI, which focuses on energy agriculture and agricultural energy consumption. In terms of energy agriculture, agriculture can be used as the supply side to provide raw materials of electricity, heat, gas and other energy. Among them, hydrogen energy is one of the fastest-growing renewable energy sources, and Zhang et al. presented an efficient hydrogen production method rivaling world advanced level (Zhang et al., 2021). Ning et al. presented a Wasserstein distributionally robust optimization model to reduce the costs of converting agricultural waste into biomass energy (Ning and You, 2019). Lee et al. studied the mechanism of $\mathrm{CO}_{2}$ in the pyrolysis process of agricultural waste to achieve waste management, energy recovery, and biochar fabrication (Lee et al., 2017). Mikulandric et al. modeled the thermal process of densification in agricultural biomass residues, and presented suggestions for process improvement
(Mikulandrić et al., 2016). Reducing greenhouse gas emissions in agricultural production to protect the environment is also a key research direction of energy agriculture. Liu et al. discussed the relationship between renewable energy-agriculture-environment in the BRICS countries (Liu et al., 2017). Fan et al. presented a land-water-energy framework in agricultural management to reduce greenhouse gas emissions (Fan et al., 2020). In terms of agricultural energy consumption, agriculture is on the load side, and the demand for energy is gradually increasing. The AEI is urgently needed to alleviate the pressure. $\mathrm{Li}$ et al. presented a breeze-driven triboelectric nanogenerator, which could be widely used in farmland environment to provide energy for agricultural sensor networks (Li et al., 2022). Energy is mainly used to regulate the microclimate in the greenhouse, including cooling, heating, irrigation, ventilation and fertilization (Ntinas et al., 2017), and the power consumption time varies according to the planting demand (Trypanagnostopoulos et al., 2017). As an advanced stage of the development of protected agriculture, the plant factory has a large demand for energy. Graamans et al. reduced the energy demand under high internal heat load by designing the exterior wall of the plant factory (Graamans et al., 2020). Agricultural biomass power generation technology is mature, and the integration of new energy and agriculture has realized engineering applications. However, a systematic theory system of AEI has not yet formed. How an AEI can promote the realization of carbon peak and carbon neutrality in agricultural production is still in a preliminary research stage.

\subsection{Simulation Technology}

The simulation of agricultural systems relies mostly on the agricultural Internet of Things, combined with the expert system. Aiello et al. established a sustainable management decision support system of greenhouses based on multi-sensor data fusion (Aiello et al., 2018). Considering the concept of the meteorological disaster early warning model, $\mathrm{Li}$ et al. established a meteorological risk management system to provide large-scale, long-term, and scalable precision agriculture services for solar greenhouses (Li et al., 2017). 
It is a very effective means of calculating power flow, with a digital power system simulation software. Liao et al. used the real time digital simulator in the actual power system driven by thermal power and $\mathrm{PV}$, and presented a dynamic calculation method based on real-time operating conditions of the system (Liao et al., 2018). The existing simulation results of agricultural and energy system are relatively mature. The agricultural system usually develops the protected agriculture monitoring system and agrometeorological disaster warning platform, which can be used to monitor the crop growth status and environment in real time and control automatically. Power simulation software has its specific applicable problems. We can build a reliable, reasonable and cost-effective energy system by utilizing appropriate power simulation technology. However, agriculture and power simulation mostly focus on their respective fields, and there is no simulation tool for an AEI.

\section{DISCUSSION}

\subsection{Difference Between AEI and Agrivoltaic}

The main difference between AEI and agrivoltaic is that, in an AEI, not only solar PV greenhouses but also energy networks need to be considered. It is commonly known that agrivoltaic engineers usually know nothing about power flow in distribution networks, and they focus only on how to lower greenhouse energy consumption. They may complain about the high electricity bill, but ignore the economic value of demand side management of greenhouses. There are relatively few studies devoted to collaborative optimization of PV greenhouse load control and energy networks. AEI can make full use of the power flow changes to offer win-win outcomes across crop production and energy networks. For example, we can use off-peak electricity to heat the greenhouses on a winter's night. From the perspective of power grid, the consumption of off-peak electricity help balance supply and demand in electric power systems. From the perspective of agriculture, the consumption of off-peak electricity means lower utility bills.

Rural roof PV can be an important power source of an AEI and an effective way to increase farmers' income. Rural roof PV can not only reduce carbon footprints, but it can also protect the roof from storms, heavy rain, wind, ice and snow. Protecting the roof from damage is the most important reason why farmers agree to install roof PV. Installation of solar PV systems in villages has accelerated the growth of distributed solar PV capacity and promoted the AEI construction.

\subsection{Complementarity Between Agriculture and Industry}

From the experiment, the agricultural scholars came to realize that poor economic benefit is the biggest obstacle to the application of the advanced facility agriculture technologies. The fundamental reason for the backwardness of rural power grid is that the value of agricultural products is lower than that of industrial products. The low load factor intensifies the economic pressure of rural power grid construction. The research has resulted in a solution of rural power gird upgrades. AEI provides a platform, on which industrial benefits flow to agriculture, while industrial carbon emissions are neutralized by agriculture. The complementarity of industry and agriculture can be realized via the tradeoff between economic output and the environment.

\subsection{Simulation Solutions}

AEI simulation models consist of the following components: stochastic weather simulation, crop simulation, greenhouse building energy simulation, solar PV simulation and energy network simulation. The investigation carried out by us has revealed that the outputs of weather and crop simulation modules are inputs of greenhouse building energy simulation. The outputs of weather simulation module also provide input data to solar PV simulation module (Fu et al., 2020b). Crop simulation module should provide carbon footprint calculation formulas. Energy production or consumption, carbon emission, and economy should be included in the greenhouse building energy simulation, solar PV simulation and energy network simulation.

We define the function modules of the AEI simulation software as follows: 1) It can carry out comprehensive safety analysis of facility agricultural environment and energy system operation thus ensuring the safe growth of crops and the safe operation of energy systems on extreme weather scenarios; 2) It can estimate the comprehensive economic benefits of facility agriculture and energy networks considering the impacts of agricultural weather, gas price and time-of-use power price on the economy of agricultural park; 3) It can track the carbon cycle of agricultural parks, taking into account not only the absorption of carbon by photosynthesis, but also the impacts of PV power, local gas and power grid carbon emission factors.

\section{CONCLUSION}

We select an agricultural energy internet with agrivoltaic systems as the main research object, and we express opinions in an argument over the combination of energy internet and agricultural engineering. The scientific opinions include the following technologies: utilizing simulation to conduct a weather impact analysis; utilizing simulation to identify agrometeorological risks and energy security risks; utilizing simulation to evaluate environmental and economic trade-offs. The framework of agricultural energy internet should incorporate the interactions between agricultural production and energy networks. A major purpose of this research is to estimate carbon emissions and economic benefits of an agricultural park under different weather conditions. Agricultural energy internet simulation is an approach used to support for collaborative planning of agrivoltaic systems and energy networks, and it is also a key technology of collaborative control of environment in facility agriculture and energy networks. 


\section{AUTHOR CONTRIBUTIONS}

All authors listed have made a substantial, direct, and intellectual contribution to the work and approved it for publication.

\section{REFERENCES}

Aiello, G., Giovino, I., Vallone, M., Catania, P., and Argento, A. (2018). A Decision Support System Based on Multisensor Data Fusion for Sustainable Greenhouse Management. J. Clean. Prod. 172, 4057-4065. doi:10.1016/j.jclepro.2017.02.197

Fan, X., Zhang, W., Chen, W., and Chen, B. (2020). Land-water-energy Nexus in Agricultural Management for Greenhouse Gas Mitigation. Appl. Energ. 265, 114796. doi:10.1016/j.apenergy.2020.114796

Fu, X., Guo, Q., and Sun, H. (2020). Statistical Machine Learning Model for Stochastic Optimal Planning of Distribution Networks Considering a Dynamic Correlation and Dimension Reduction. IEEE Trans. Smart Grid 11, 2904-2917. doi:10.1109/tsg.2020.2974021

Fu, X., Yang, D., Guo, Q., and Sun, H. (2020). Security Analysis of a Park-Level Agricultural Energy Network Considering Agrometeorology and Energy Meteorology. CSEE J. Power Energ. Syst. 6, 743-748. doi:10.17775/ CSEEJPES.2019.03230

Fu, X., Zhou, Y., Yang, F., Ma, L., Long, H., Zhong, Y., et al. (2021). A Review of Key Technologies and Trends in the Development of Integrated Heating and Power Systems in Agriculture. Entropy 23, 260. doi:10.3390/e23020260

Graamans, L., Tenpierik, M., van den Dobbelsteen, A., and Stanghellini, C. (2020). Plant Factories: Reducing Energy Demand at High Internal Heat Loads through Façade Design. Appl. Energ. 262, 114544. doi:10.1016/j.apenergy.2020.114544

Lee, J., Yang, X., Cho, S.-H., Kim, J.-K., Lee, S. S., Tsang, D. C. W., et al. (2017). Pyrolysis Process of Agricultural Waste Using CO2 for Waste Management, Energy Recovery, and Biochar Fabrication. Appl. Energ. 185, 214-222. doi:10. 1016/j.apenergy.2016.10.092

Li, M., Chen, S., Liu, F., Zhao, L., Xue, Q., Wang, H., et al. (2017). A Risk Management System for Meteorological Disasters of Solar Greenhouse Vegetables. Precision Agric. 18, 997-1010. doi:10.1007/s11119-017-9514-9

Li, X., Cao, Y., Yu, X., Xu, Y., Yang, Y., Liu, S., et al. (2022). Breeze-driven Triboelectric Nanogenerator for Wind Energy Harvesting and Application in Smart Agriculture. Appl. Energ. 306, 117977. doi:10.1016/j.apenergy.2021. 117977

Liao, S., Xu, J., Sun, Y., Bao, Y., and Tang, B. (2018). Wide-area Measurement System-Based Online Calculation Method of PV Systems De-loaded Margin for Frequency Regulation in Isolated Power Systems. IET Renew. Power Gener. 12 (3), 335-341. doi:10.1049/iet-rpg.2017.0272

Liu, X., Zhang, S., and Bae, J. (2017). The Nexus of Renewable Energy-AgricultureEnvironment in BRICS. Appl. Energ. 204, 489-496. doi:10.1016/j.apenergy. 2017.07.077

\section{FUNDING}

This study is supported by the National Natural Science Foundation of China under Grant 52007193 and The 2115 Talent Development Program of China Agricultural University.

Mikulandrić, R., Vermeulen, B., Nicolai, B., and Saeys, W. (2016). Modelling of thermal Processes during Extrusion Based Densification of Agricultural Biomass Residues. Appl. Energ. 184, 1316-1331. doi:10.1016/j.apenergy.2016. 03.067

Ning, C., and You, F. (2019). Data-driven Wasserstein Distributionally Robust Optimization for Biomass with Agricultural Waste-To-Energy Network Design under Uncertainty. Appl. Energ. 255, 113857. doi:10.1016/j.apenergy.2019. 113857

Ntinas, G. K., Neumair, M., Tsadilas, C. D., and Meyer, J. (2017). Carbon Footprint and Cumulative Energy Demand of Greenhouse and Open-Field Tomato Cultivation Systems under Southern and Central European Climatic Conditions. J. Clean. Prod. 142 (Part 4), 3617-3626. doi:10.1016/j.jclepro. 2016.10.106

Trypanagnostopoulos, G., Kavga, A., Souliotis, M., and Tripanagnostopoulos, Y. (2017). Greenhouse Performance Results for Roof Installed Photovoltaics. Renew. Energ. 111, 724-731. doi:10.1016/j.renene.2017.04.066

Xueqian, Fu. (2020). Zhou Yazhong, Sun Hongbin, Wang Yang. Park-Level Agricultural Energy Internet: Concept, Characteristic and Application Value. Trans. Chin. Soc. Agric. Eng. (Transactions CSAE) 36 (12), 152-161. doi:10. 11975/j.issn.1002-6819.2020.12.019

Zhang, K., Zhou, B., Or, S. W., Li, C., Chung, C. Y., and Voropai, N. I. (2021). "Optimal Coordinated Control of Multi-Renewable-To-Hydrogen Production System for Hydrogen Fueling Stations. IEEE Transactions on Industry Applications. doi:10.1109/TIA.2021.3093841

Conflict of Interest: The authors declare that the research was conducted in the absence of any commercial or financial relationships that could be construed as a potential conflict of interest.

Publisher's Note: All claims expressed in this article are solely those of the authors and do not necessarily represent those of their affiliated organizations, or those of the publisher, the editors and the reviewers. Any product that may be evaluated in this article, or claim that may be made by its manufacturer, is not guaranteed or endorsed by the publisher.

Copyright (C) $2022 \mathrm{Fu}$ and Yang. This is an open-access article distributed under the terms of the Creative Commons Attribution License (CC BY). The use, distribution or reproduction in other forums is permitted, provided the original author(s) and the copyright owner(s) are credited and that the original publication in this journal is cited, in accordance with accepted academic practice. No use, distribution or reproduction is permitted which does not comply with these terms. 